\title{
PENDUGAAN ZONA AKUIFER DENGAN METODE GEOLISTRIK RESISTIVITY KONFIGURASI SCHLUMBERGER DI DESA JENETALLASA KECAMATAN BANGKALA KABUPATEN JENEPONTO
}

\author{
Musriadi $^{1}$, Ayusari Wahyuni ${ }^{1}$, Andi Syam Rizal ${ }^{1}$, Sahrul Sani Saparuddin ${ }^{1}$, dan \\ Andi Devi Sri Anjani ${ }^{1}$ \\ Jurusan Fisika, Fakultas Sains dan Teknologi, Universitas Islam Negeri Alauddin Makassar \\ email: musriadi21musa@gmail.com, ayusari_wahyuni@uin-alauddin.ac.id, andirizal.itb@gmail.com, \\ sahrul.sani.saparuddin@uin-alauddin.ac.id, andi.devi.srianjani@uin-alauddin.ac.id
}

\begin{abstract}
Springs are a problem in areas where geographic conditions are predominantly hot with low annual rainfall. Water is one of the basic needs for all living things on Earth, both plants, animals and especially humans. If there is a scarcity of spring sources, it is certain that daily activities are very disturbed. Scarcity of springs as happened in Jenetallasa Village greatly influences community activities in the Village. Prolonged drought results in increasingly severe water scarcity that occurs. Based on this problem, a field study was conducted to estimate the aquifer zone. Aquifers are a source of springs located in cavities brought under the surface of the ground which reminisce or flow. Aquifers themselves can be predicted without existence of drilling or excavation. Detection of aquifers can be done using geoelectric methods with different configurations. Our field study this time uses a schlumberger configuration with a length of 120 meters with an approximate depth of 60 meters below ground level.
\end{abstract}

Keywords: aquifer zone, resistivity geoelectric method and schlumberger configuration.

\section{PENDAHULUAN}

Air sangat berperan penting dalam kehidupan, dimana air menjadi salah satu kebutuhan pokok bagi semua mahluk hidup, baik tumbuhan, hewan dan terutama manusia. Penigkatan jumlah penduduk berbanding lurus dengan besarnya kebutuhan akan air bersih. Besarnya jumlah penduk yang tidak diimbangi dengan keberadan sumber mata air akan menyebabkan kelangkaan sumber mata air. Kelangkaan sumber mata air seperti yang terjadi di Desa Jenetallasa sangat berpengaruh terhadap aktivitas masyarakat.

Kemarau yang berkepanjangan mengakibatkan semakin parahnya kelangkaan air yang terjadi. Sumber mata air bawah tanah atau akuifer menjadi salah satu alternatif sumber mata air di Desa Jenetallasa.. Akuifer sendiri dapat diperediksi keberadaanya tanpa melakukan pengeboran atau penggalian. Pendeteksian akuifer dapat dilakukan dengan menggunakan metode geolistrik tahanan jenis dengan konfigurasi yang berbeda-beda.

Geolistrik merupakan salah satu metode geofisika yang memanfaatkan arus dan tegangan sebagai penginjeksinya. Dimana metode geolistrik ini dilakukan 
dengan menginjeksikan arus kedalam lapisan tanah dengan memanfaatkan hukumhukum kelistrikan. Metode geolistrik itu sendiri dalam kegiatan eksplorasi terbeagi dalam beberapa konfigurasi diantaranya konfigurasi schlumberger, wernner, polidipol, dan dipol-dipol. Tiap-tiap konfigurasi memiliki kelebihanya masing-masing dalam pendugaan bawah permukaan.

Geolistrik resisitivitas dengan konfigurasi Schlumberger merupakan salah satu metode geolistrik dengan susunan elektroda tertentu yang dapat mendeteksi, mengukur dan menduga keberadaan jenis material di bawah permukaan bumi. Hasil interpretasi konfigurasi Schlumberger berupa litologi batuan berdasarkan nilai resistivitas perkedalaman. Dimana sistem aturan spasi elektroda pada konfigurasi schlumberger disusun secara konstan dengan catatan faktor " $n$ " untuk konfigurasi ini adalah perbandingan jarak antara elektroda A-M (atau B-N) adalah $2 n a+a$. Proses penentuan resistivitas menggunakan 4 buah elektroda yang diletakkan dalam sebuah garis lurus. Tujuan penelitian ini adalah untuk mencari lapisan pembawa air tanah (akuifer) di Kabupaten Jeneponto, Kecamatan Bangkala, Desa Jenetallasa dengan menggunakan metode geolistrik resistivitas dengan konfigurasi schlumberger.

\section{METODE PENELITIAN}

Penelitian ini dilakukan dengan menggunakan alat dan bahan berupa, resistivitimeter, elektroda arus dan tegangan, aki, kabel, palu, kompas geologi, GPS, HT (Halky Talky), meteran, alat tulis menulis dan payung.Prosedur pelaksanaan penelitian ini diawali dengan survei lapangan sebelum melakukan pengambilan data. Kemudian menentukan lokasi penempatan patok atau elektroda arus dan tegangan. Kemudian melakukan pengukran lintasan elektroda sepanjang $120 \mathrm{~m}$. Memasang satu elektroda di titik sounding serta sebagai tempat acuan memasang roll meter. Menentukan jarak spasi elektroda arus dari titik sounding sepanjang $3 \mathrm{~m}$ dan elektroda potensial dari titik sounding sepanjang $1,5 \mathrm{~m}$, kemudian mematok elektroda tersebut sesuai jarak yang telah ditentukan. Membentangkan kabel dan menghubungkan pada masing-masing elektroda arus dan tegangan serta alat resistivitimeter seperti pada gambar 1 berikut.

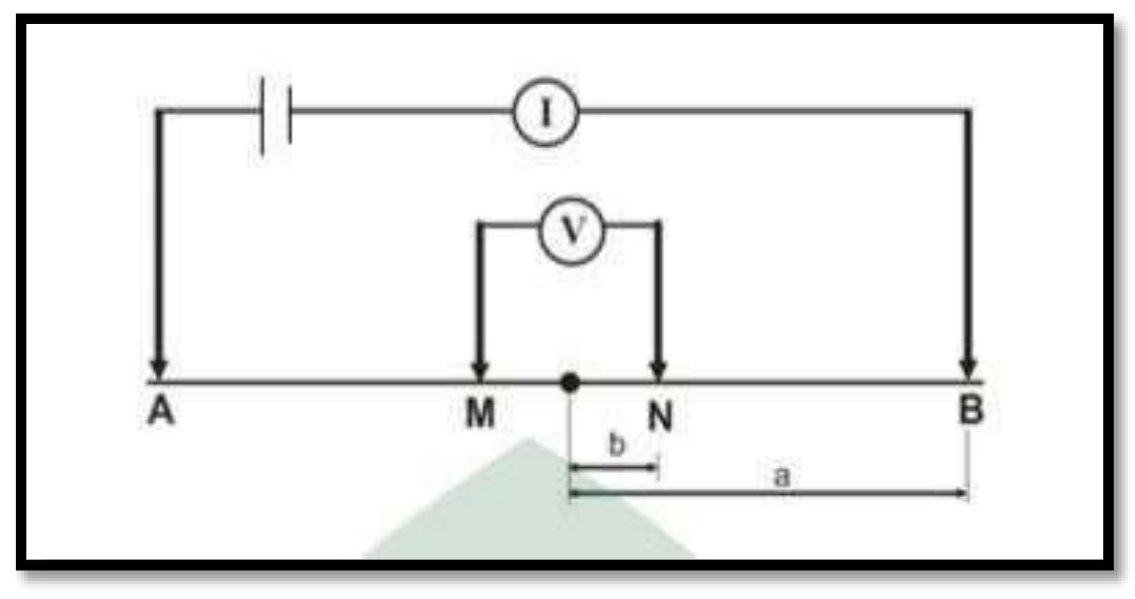

Gambar 1. Rangkaian konfigurasi schlumberger 
Adapun cara kerjanya adalah mengaktifkan resistivitimeter dengan menekan tombol "On". Menekan tombol tes (AB dan MN) sebagai pengetes elektroda terhubung dengan baik. Menekan tombol inject (sampai berbunyi 3 kali) kemudian menekan tombol Hold pada multimeter yang ada pada resistivitimeter secara bersamaan. Mencatat nilai yang terbaca pada multimeter yang ada pada resistivitimeter. Mengubah jarak $A$ dan B untuk data selanjutnya sesuai dengan tabel konfigurasi schlumberger dan, mengulangi kegiatan kembali dengan mengubah jarak $\mathrm{M}$ dan $\mathrm{N}$ dari titik sounding.

\section{HASIL DAN PEMBAHASAN}

Berdasarkan data pada geologi lembar Ujung Pandang Benteng dan Sinjai Sulawesi RAB Sukanto dan Sam Suprianta (1982), dengan skala 1: 200.000 bahwa daerah praktikum lapangan ini memiliki struktur geologi yang berkembang terdiri atas sesar naik, sesar mendatar, sesar normal dan lipatan yang pembentuknya berhubungan dengan tektonik regional Sulawesi dan sekitarnya. Lokasi penelitian ini berada pada jenis formasi endapan aluvium dan pantai meliputi batuan sedimen laut berselingan dengan batuan gunung api muda, formasi tonasa meliputi batugamping dan untuk batuan trobosan meliputi basal dan retas basal. Pada hasli yang diperoleh pada tabel di atas dapat dilakukan interpretasi data dan dibandingkan dengan hasil data pada peta geologi dengan menggunakan tabel resistivitas menurut Tellford (1960).

Pada pengukuran ini menggunakan konfigurasi schlumberger dengan panjang lintasan $120 \mathrm{~m}$, dengan jarak spasi antar elektroda $5 \mathrm{~m}$. Pengukuran ini diperkiran kedalaman yang diukur ${ }^{1 / 4}$ dari panjang lintasan. Prinsip kerja dari konfigurasi schlumberger dengan menggunakan 4 buah elektroda, 2 elektroda arus dan 2 elektroda potensial. Dimana jarak spasi antara elektroda arus dan tegangan dengan spasi $5 \mathrm{~m}$, dan jarak spasi 2 elektroda tegangan dengan spasi 2,5m.

\section{Lintasan 1}

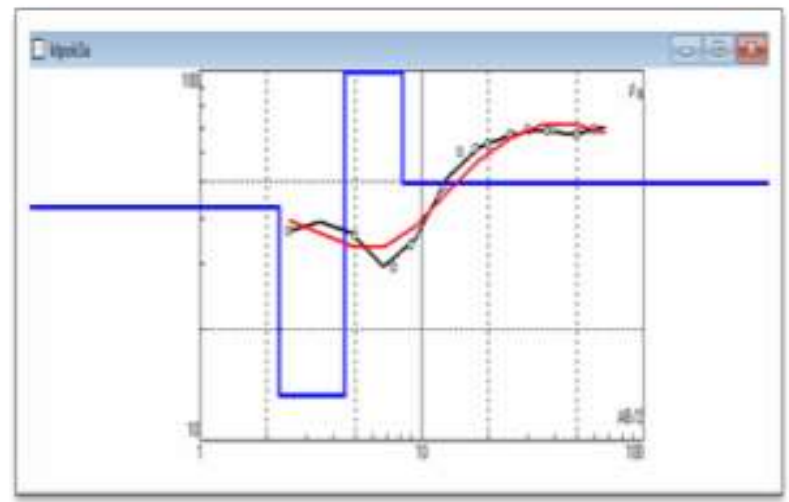

Gambar 1. Grafik hasil pengukuran pada lintasan 1

Pada gambar grafik dapat diliahat ada tiga jenis warna garis kurva, dimana garis kurva warna biru menunjukan nilai rho hasil komputasi, sedangkan warna merah pada grafik menunjukan kurva sintesis dan kurva warna hitam pada grafik menunjukan data lapangan yang diperoleh pada saat pengukuran. Data pada kolom tersebut kemudian dimasukkan kedalam tabel sebagai data hasil interperetasi. 
Tabel 1. Interperensi data

\begin{tabular}{|c|c|c|c|c|}
\hline No & $\begin{array}{c}\text { Nilai Resistivitas } \\
(\Omega \mathrm{m})\end{array}$ & $\begin{array}{c}\text { Ketebalan } \\
(\mathrm{m})\end{array}$ & $\begin{array}{c}\text { Kedalaman } \\
(\mathrm{m})\end{array}$ & $\begin{array}{c}\text { Hasil Interperensi } \\
\text { Data }\end{array}$ \\
\hline 1 & 42,9 & 2.28 & 2,28 & Batuan Serpih \\
\hline 2 & 13,2 & 2.19 & 4,47 & Akuiver \\
\hline 3 & 424 & 3.17 & 8,2 & Lempung \\
\hline 4 & 49,7 & 3.18 & 8,2 & \\
\hline
\end{tabular}

Berdasarkan data pengukuran yang diperoleh dengan menggunakan konfigurasi Schlumberger menggunakan software Ip2win. Untuk hasil pengukuran lintasan pertama dapat diduga dengan nilai resistivitas $42,9 \Omega \mathrm{m}$ dengan ketebalan $2,28 \mathrm{~m}$ sebagai lapisan utama yaitu batuan serpih. Nilai resistivitas 13,2 dengan kedalaman 4,47 terdapat akuifer, resistivitas 424 pada kedalaman $8.2 \mathrm{~m}$ diduga batuan gamping dan nilai sensitivitas 49,7 dengan kedalaman 8,2 $\mathrm{m}$ batuan lempung dan persen eror $7,43 \%$. Seperti terlihat pada gambar lintasan pertama

\section{Lintasan 2}

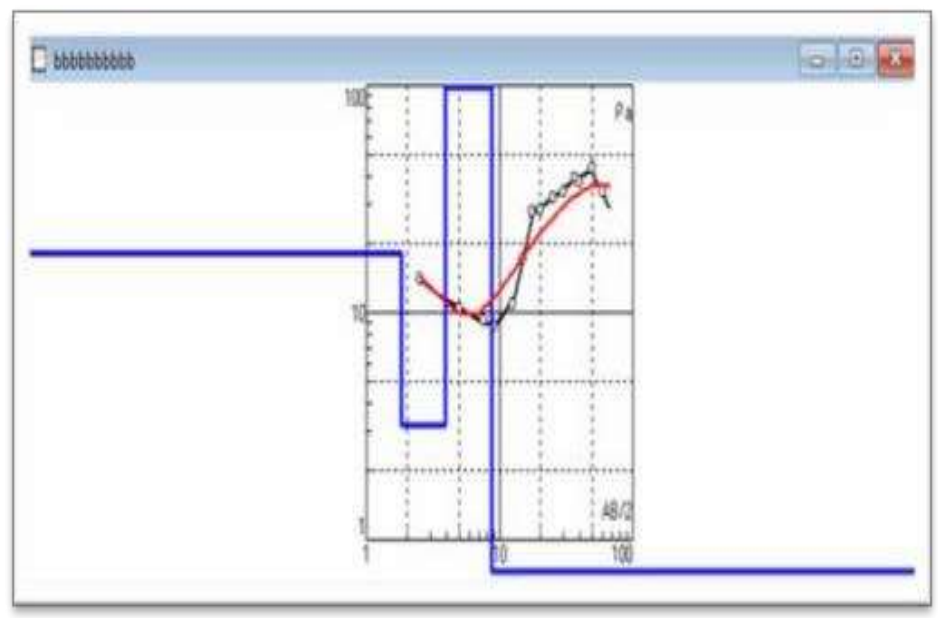

Gambar 2. Grafik hasil pengukuran pada lintasan 2 
Tabel 2. Interperensi data

\begin{tabular}{|c|c|c|c|c|}
\hline No & $\begin{array}{c}\text { Nilai Resistivitas } \\
(\Omega \mathrm{m})\end{array}$ & $\begin{array}{c}\text { Ketebalan } \\
(\mathrm{m})\end{array}$ & $\begin{array}{c}\text { Kedalaman } \\
(\mathrm{m})\end{array}$ & $\begin{array}{c}\text { Hasil Interperensi } \\
\text { Data }\end{array}$ \\
\hline 1 & 18,1 & 1,81 & 1,81 & Gabro \\
\hline 2 & 3,21 & 2,13 & 3,94 & Gatuan pasir \\
\hline 3 & 544 & 4,18 & 8,75 & Air tanah \\
\hline 4 & 0,5 & 4,19 & 8,75 & \\
\hline
\end{tabular}

Pada lintasan kedua di duga nilai resistivitas 18,1 dengan kedalaman 18,1 m terdapat lapisan utama yaitu batuan gabro, resistivitas yang ke dua 3,21 dengan kedalaman 3,94 $\mathrm{m}$ terdapat batuan batuan pasir, resistivitas yang ketiga 544 dengan kedalaman 8,75 terdapat batuan gamping, dan yang terakhir nilai resistivitas 0,5 dengan ketebalan 8,75 m terdapat air tanah dan persen eror $19,7 \%$, seperti pada gambar grafik lintasan kedua.

Gambar 3 merupakan penggabungan lintasan lintasan 1 dan 2 yang menunjukkan adanya keterkaitan antara data geologi dan geofisika. Pada kedalaman 4,47 $\mathrm{m}$ dan 8,75 $\mathrm{m}$ terlihat hubungan akuifer dengan air tanah pada lintasan 1 ke lintasan 2. Pada kedalaman ini tentunya sangat memudahkan masyarakat untuk mendapatkan air tanah dengan ketebalan 4,19 m. Masyarakat dengan mudah melakukan penggalian ataupun pengeboran air tanah dengan akses yang murah dan terjangkau.

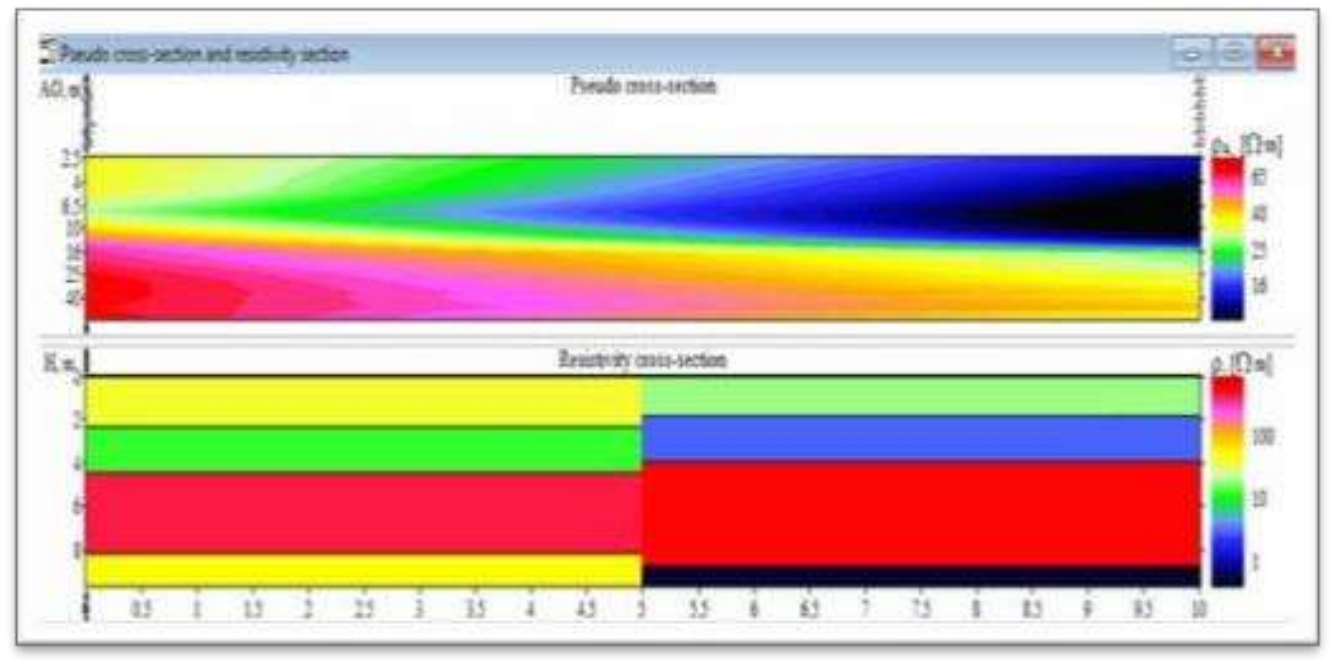

Gambar 3. Pseducrossection lintasan 1 dan 2 


\section{KESIMPULAN}

Kesimpulan pada penelitian ini adalah dalam menentukan sumber air atau mencari lapisan air tanah menggunakan metode geolistrik yaitu metode schlumberger. Konfigurasi Schlumberger adalah konfigurasi dengan sistem aturan spasi yang konstan dengan catatan faktor " $n$ " untuk konfigurasi ini adalah perbandingan jarak antara elektroda A-M (atau B-N) adalah $2 n a+a$. Proses penentuan resistivitas menggunakan 4 buah elektroda yang diletakkan dalam sebuah garis lurus. Pada pengukuran ini jarak elektroda arus ke potensial $5 \mathrm{~m}$ dan jarak elektroda kedua potensial 2,5 $\mathrm{m}$. Pengukuran dilakukan dengan dua lintasan, dimana lintasan pertama pendugaan terdapat akuifer dengan nilai resistivitas 13,2 $\Omega \mathrm{m}$ dengan kedalaman 4,47 $\mathrm{m}$. Pada lintasan kedua pendugaan terhadap pengukuran ditemukan air tanah dengan nilai resistivitas $0,5 \Omega \mathrm{m}$ dengan kedalaman $8,75 \mathrm{~m}$.

\section{DAFTAR PUSTAKA}

Andriyani, Satuti. dkk. 2010. Metode Geolistrik Imaging Konfiguration DipoleDipole Digunakan Untuk Penelusuran Sistem Sungai Bawah Tanah Pada Kawasan Karts Di Pacitan, Jawa Timur. Universitas Sebelas Maret Surakarta (Diakses tanggal 18 september 2019).

Azwar, Hendri. 2009. Pemodelan Lapisan Air Tanah Dalam (Akuifer) di Desa Telogerejo Kab.Demak Berdasarkan Data Tahanan Jenis. Jakarta: Program Studi Fisika Universitas Islam Negeri Syarif Hidayatullah.

Darsono. 2016. "Identifikasi Akuifer Dangkal dan Akuifer Dalam dengan Metode Geolistrik (Kasus: Di Kecamatan Masaran)". Indonesian Journal of Applied Physics, ISSN: 2089-0133. Vol.2 Hal:40-49. Surabaya: Universitas Sebelas Maret.

Santoso, Budy. 2016. Penerapan Metode Geolistrik-2D Untuk Identifikasi Amblasan Tanah Dan Longsoran Di Jalan Tol Semarang-Solo KM 5 $5^{+400}-K M$ $5^{+800}$. Universitas Padjajaran (Diakses tanggal 18 september 2019).

Setiono, Dedi.dkk. 2018. Penyelidikan Zona Akuifer Menggunakan Geolistrik Metode Schlumberger di Sekitar Pantai Utara Kecamatan Kramat, Suradadi dan Warureja Kabupaten Tegal, Jawa Tengah. Semarang: Program Studi Teknik Geologi Universitas Diponegoro.

Syamrizal. 2013. Aplikasi Metode Resistivitas Untuk Identifikasi Litologi Batuan.

Wardana, Galang Gerindra. 2019. Identifikasi Zona Akuifer Air Tanah Menggunakan Metode Vertical Electrical Sounding (VES) Pada Derah Banyumas Kabupaten Pringsewu. Lampung: Jurusan Teknik Geofisika Universitas Lampung. 